\title{
CONTROL OF HYPERTENSION AFTER ROUX-EN-Y GASTRIC BYPASS AMONG OBESE DIABETIC PATIENTS
}

\author{
Everton CAZZO, Martinho Antonio GESTIC, Murillo Pimentel UTRINI, \\ Ricardo Rossetto MACHADO, José Carlos PAREJA and Elinton Adami CHAIM
}

\begin{abstract}
Context - Hypertension is a common disorder in general practice and has a widely known association with type 2 diabetes mellitus. Low adhesion to clinical treatment may lead to poor results. Obesity surgery can bring early and relevant resolution rates of both morbidities. Objective - To describe hypertension evolution after Roux-en-Y gastric bypass in patients with type 2 diabetes mellitus. Method - Descriptive observational study designed as a historical cohort of 90 subjects with hypertension and diabetes who underwent Roux-en-Y gastric bypass and were evaluated before and after surgery. Results - It was observed a hypertension resolution rate of $85.6 \%$ along with markedly decrease in anti-hypertensive usage. Mean resolution time was 3.2 months. Resolution was associated with homeostasis model assessment - insulin resistance, preoperative fasting insulin, anti-hypertensive usage, hypertension time, body mass index and percentage of weight loss. Resolution of hypertension was not statistically associated with diabetes remission within this sample. Conclusion - Roux-en-Y gastric bypass was a safe and effective therapeutic tool to achieve hypertension resolution in patients who also had diabetes mellitus.
\end{abstract}

HEADINGS - Hypertension. Diabetes Mellitus. Roux-en-Y anastomosis. Gastric bypass. Bariatric surgery. Obesity.

\section{INTRODUCTION}

Essential hypertension is a disorder commonly observed in general practice. Its association with type 2 diabetes mellitus (T2DM) is widely recognized and it was already reported that $40 \%$ to $80 \%$ of all diabetic patients may probably be hypertensive as well ${ }^{(3,26)}$. As a result of impaired autonomic function and extensive organ damage, higher blood pressure variability, marked orthostatic responses and impaired nocturnal blood pressure reductions are common features in diabetic individuals ${ }^{(26)}$. It is postulated that there is a substantial interconnection between metabolic factors and hypertension, beyond what we comprehend at the moment ${ }^{(4,20)}$. The underlying pathophysiology of this interplay is yet to be understood, however increasing evidence regarding this topic is emerging. Among nondiabetic hypertensive patients, poor blood pressure control is associated with two fold increased risk of diabetes $^{(4,20)}$. The benefits of reducing blood pressure in diabetic patients have been clearly shown by the results of the Hypertension Optimal Treatment ${ }^{(13)}$ and United Kingdom Prospective Diabetes Study(30) studies among others ${ }^{(7,8,10,14,29)}$. Diabetic patients may require more intense treatment to achieve the same blood pressure levels as nondiabetic individu$\mathrm{als}^{(18)}$. Adhesion to long term nonpharmacological and drug treatments constitute a point of concern once there are reports showing consistently low rates of complete adherence to both, especially in poorly developed regions ${ }^{(30)}$. Surgery for morbid obesity has become a standard treatment option leading to markedly lower morbidity ${ }^{(22)}$. Global impact of surgery on long term mortality reduction has already been observed on obese patients with $40 \%$ reduction on all causes mortality, $56 \%$ on coronary heart disease, $92 \%$ on diabetes complications and $60 \%$ on any type of cancer ${ }^{(1)}$. Improvement of metabolic comorbidites is observed early after surgery and it is not completely comprehended ${ }^{(22,23)}$. It is known that most bariatric procedures lead to increased level of gastrointestinal hormones called incretins that raise insulin sensitivity. This mechanism is probably reinforced by late weight $\operatorname{loss}^{(23)}$.

This study aims to describe hypertension evolution after Roux-en-Y gastric bypass in patients with T2DM.

\section{METHODS}

This study is descriptive and longitudinal and designed as a retrospective cohort. It included obese 
subjects which had T2DM according to American Diabetes Association (ADA) criteria who were submitted to open Roux-en-Y gastric bypass (RYGB) at Hospital de Clinicas - Unicamp between 2000 and 2010. This study was submitted and approved by the local Research Ethics Committee. Surgery was indicated based on the National Institutes of Health Consensus Statement criteria ${ }^{(12)}$. Sample size estimation was performed through single proportion formula with $95 \%$ confidence interval ${ }^{(5)}$. Precision was set at $10 \%$ and the calculated sample size was 84 . Exclusion criteria for this study were: individuals who had undergone other bariatric procedures after RYGB, whose postoperative follow-up time was less than 12 months, and who belonged to vulnerable groups (mentally ill, institutionalized or aged under 18 years old).

From 672 subjects who underwent RYGB, 90 who filled criteria for both T2DM as specified by American Diabetes Association $^{(2)}$ and hypertension according to Brazilian guidelines $^{(25)}$, and had been followed for at least 12 months were included. Main characteristics regarding demographics, presence of hypertension, and preoperative pharmacological treatments were assessed. Anti-hypertensive usage before and after surgery were evaluated. Comparisons were made between the periods immediately before and at least one year after surgery, in order to measure the impact of the procedure on resolution of T2DM and hypertension. Some biochemical characteristics were evaluated included fasting glucose, fasting insulin, hemoglobin A1c, homeostasis model assessment -insulin resistance (HOMA-IR) in order to identify correlations with hypertension resolution or improvement. Hypertension resolution was achieved through three non-consecutive measures below 130/85 $\mathrm{mmHg} \mathrm{g}^{(25)}$. T2DM resolution was achieved according to American Diabetes Association criteria $(\mathrm{FG}<100 \mathrm{mg} / \mathrm{dL}$ and $\mathrm{HbA} 1 \mathrm{c} \leq 6,5 \%)^{(2)}$.

\section{Statistical Analysis}

The baseline characteristics of patients are described and then compared with postoperative period. Data were examined for normality according to the Pearson's chisquared test. For univariate analysis of categorical variables, chisquare and Fisher's exact tests were carried out. The McNemar test was used for comparison of proportions between the two periods. To identify possible factors associated to the studied outcomes it was used the multiple logistic regression analysis. The significance level adopted was $5 \%$ ( $P$-value $<0.05$ ). For execution of analysis it was used Statistic Analysis System (SAS) software for Windows version 9.2.

\section{RESULTS}

Of 90 patients selected for study, $69(76.7 \%)$ were female and $21(23.3 \%)$ were male. The mean age at surgery was 46 (range, 22-64) years. The mean postoperative and follow-up time was 35.1 (range 12-120) months. Main subject characteristics at baseline are summarized on Table 1 .
TABLE 1. Subject characteristics at baseline

\begin{tabular}{ll}
\hline Gender & \\
$\quad$ Male & $23.3 \%$ \\
Female & $76.7 \%$ \\
Age & $46 \pm 10.8 \mathrm{yrs}$ \\
BMI & $44.4 \pm 8.9(35-80.8) \mathrm{kg} / \mathrm{m}^{2}$ \\
Weight (kg) & $102.9 \pm 18.7(72-180) \mathrm{kg}$ \\
Postoperative follow-up & $34.8 \pm 25.7$ months \\
Comorbidities & \\
$\quad$ Hypertension & $100 \%$ \\
$\quad$ T2DM & $100 \%$ \\
$\quad$ Dyslipidemia & $87.8 \%$ \\
Pharmacological treatments & \\
$\quad$ Insulin & $21.1 \%$ \\
Oral Hypoglycemiants & $98.9 \%$ \\
Anti-lipids & $76.7 \%$ \\
Anti-hypertensive & $100 \%$ \\
\hline
\end{tabular}

Mean hospital stay was 4.2$\} 0.3$ days. Overall surgical morbidity was $11.1 \%$ and the main complications were wound infection $(4,4 \%)$ and atelectasis $(2.2 \%)$. There was no mortality.

Patients experienced a significant decrease of body mass index from 44.5$\} 8.8 \mathrm{~kg} / \mathrm{m}^{2}$ to 31.7$\} 7.9 \mathrm{~kg} / \mathrm{m}^{2}(P<0.001)$. Mean weight loss was 29.7$\} 9.3 \mathrm{~kg}(P<0.0001)$. Percentage of excess weight loss after surgery was 71.5$\} 27.7 \%$. Preoperatively, $100 \%$ patients had hypertension. After surgery, there were $13(14.4 \%)$ who still had hypertension, leading to a resolution rate of $85.6 \%(P<0.0001)$.

There was a markedly reduction on anti-hypertensive classes usage after surgery from 1.6 (range, 1-4) to 0.5 (range, 0 -2) drug $(P<0.0001)$. Among patients who did not achieve hypertension resolution it was observed significant reduction on number of anti-hypertensive classes usage, from 2.3 before to 1.3 after surgery $(P=0.001)$. Mean resolution time was 3.2 months (range, 1-12). According to multivariate analysis, the factors statistically associated to hypertension resolution were: HOMA - IR $(P=0.0482)$, postoperative body mass index $(P=0.0017)$, hypertension duration $(P=0.0321)$, preoperative fasting insulin $(P=$ $0.0385)$, number of preoperative anti-hypertensive classes $(P=0.0072)$, number of postoperative antihypertensive classes $(P=0.0002)$ and percentage of excess weight loss $(P=0.0011)$. Table 2 shows resolution rates varied according to hypertension severity grade as classified by Brazil-

TABLE 2. Resolution of Hypertension according to preoperative severity grade

\begin{tabular}{lll}
\hline Severity grade & N $(\%)$ & Resolution $(\%)$ \\
\hline I & $34(37.8)$ & $34(100)$ \\
II & $40(44.4)$ & $33(82.5)$ \\
III & $16(17.8)$ & $10(62.5)$ \\
Total & $90(100)$ & $77(85.6)$ \\
\hline
\end{tabular}

$\mathrm{N}$ : number of patients 
ian guidelines ${ }^{(25)}$. Resolution rates stratified according to preoperative number of anti-hypertensive classes are shown on Table 3.

TABLE 3. Resolution of Hypertension according to number of preoperative anti-hypertensive classes

\begin{tabular}{lcc}
\hline Anti-hypertensive classes & $\mathbf{N}(\%)$ & Resolution (\%) \\
\hline 1 & $28(31.1)$ & $28(100)$ \\
2 & $36(40)$ & $35(97.2)$ \\
3 & $17(18.9)$ & $11(64.7)$ \\
4 & $9(10)$ & $3(33.3)$ \\
Total & $90(100)$ & $77(85.6)$ \\
\hline
\end{tabular}

$\mathrm{N}$ : number of patients

Before surgery, all patients had T2DM. Postoperatively nine $(10 \%)$ still had it. Its resolution rate was $90 \%(P<0.0001)$. Analyzing hypertension resolution along with diabetes it was observed that $77.8 \%$ experienced resolution of both disorders, $12.2 \%$ had only diabetes resolution, $7.8 \%$ had only hypertension resolution and $2.2 \%$ had none. The association between resolution of both comorbidities were not statistically significant $(P=0.6127)$.

\section{DISCUSSION}

There is clear evidence about the great benefits of RYGB on hypertension and T2DM, especially when compared to the effectiveness of clinical treatment ${ }^{(23,24)}$. It is known that this operation brings this impact through a complex array of metabolic mechanisms which involve increased incretin secretion due to duodenal exclusion or early arrival of nu- trients on ileum; weight loss; decreased hepatic uptake of lipids; and changes on adipocin profile ${ }^{(17,23,28)}$.

This study showed a high hypertension resolution rate $(85.6 \%)$ among previously diabetic patients. T2DM resolution was also high $(90.6 \%)$ although both resolutions were not statistically linked. This may be caused by the multifactorial nature of both disorders and the intrincate pathways by which they are associated ${ }^{(3,20,26}$. A metanalysis involving 136 studies and 22,094 patients made by Buchwald et al.(6) revealed an overall resolution of hypertension of $75.4 \%$. In a review of 19 studies carried out by Maggard et al. ${ }^{(19)}$ resolution rates varying from $25 \%$ to $75 \%$ were observed. According to most studies, hypertension control appears to be so linked to improvement on insulin sensitivity and proinflammatory state as to proper weight $\operatorname{loss}^{(11,15,16,27)}$. Previous Brazilian reports have shown similar results ${ }^{(9,21)}$.

Among the factors statistically associated with hypertension resolution in this sample, there were some related to insulin sensitivity (HOMA-IR, preoperative fasting insulin), others to hypertension severity (anti-hypertensive usage, hypertension duration) and still others directly linked to ponderal status (body mass index, percentage of excess weight loss). This finding clearly reinforces the complex pathophysiology of hypertension and its mechanisms of resolution after RYGB.

\section{CONCLUSION}

There was an important impact of RYGB on hypertension evolution in diabetic patients, thus this operation may be considered a safe and effective therapeutic option within this group.

Cazzo E, Gestic MA, Utrini MP, Machado RR, Pareja JC, Chaim EA. Controle da hipertensão arterial após bypass gástrico em Y-de-Roux em obesos diabéticos. Arq Gastroenterol. 2014,51(1):21-4.

RESUMO - Contexto - A hipertensão arterial é uma patologia frequente na prática clínica e sua associação ao diabetes mellitus tipo 2 é amplamente conhecida. A baixa adesão ao tratamento clínico comumente leva a resultados precários. A cirurgia bariátrica é capaz de promover precocemente índices elevados de resolução de ambas as morbidades. Objetivo - Descrever a evolução da hipertensão arterial após o bypass gástrico em Y-de-Roux em indivíduos diabéticos. Metodos - Estudo descritivo observacional de coorte histórica envolvendo 90 indivíduos com hipertensão e diabetes que foram submetidos ao bypass gástrico em Y-de-Roux, avaliados antes e após o procedimento. Resultados - Foi observado índice de resolução da hipertensão de $85.6 \%$ associado a grande redução na utilização de anti-hipertensivos. O tempo médio de resolução foi de 3.2 meses. A resolução esteve associada ao modelo de avaliação homeostática (HOMA) - resistência insulínica, insulina basal pré-operatória, uso de anti-hipertensivos, tempo de hipertensão, índice de massa corpórea e percentual de perda do excesso de peso. A resolução da hipertensão não foi associada estatisticamente à remissão do diabetes na amostra estudada. Conclusão - O bypass gástrico em Y-de-Roux foi uma opção terapêutica segura e eficiente para levar à resolução da hipertensão em pacientes diabéticos.

DESCRITORES - Hipertensão. Diabetes Mellitus. Anastomose em Y-de-Roux. Derivação Gástrica. Cirurgia Bariátrica. Obesidade. 


\section{REFERENCES}

1. Adams TD, Gress RE, Smith SC, Halverson RC, Simper SC, Rosamond WD, Lamonte MJ, Stroup AM, Hunt SC. Long-term mortality after gastric bypass surgery. N Engl J Med. 2007;357:753-61.

2. American Diabetes Association. Standards of medical care in diabetes (position statement). Diabetes Care. 2005;28:S4-S36.

3. Anwer Z, Sharma RK, Garg VK, Kumar N, Kumari A. Hypertension management in diabetic patients. Eur Rev Med Pharmacol Sci. 2011;15:1256-63.

4. Arcucci O, de Simone G, Izzo R, Rozza F, Chinali M, Rao MA, Bodenizza C, De Luca N, Trimarco B. Association of suboptimal blood pressure control with body size and metabolic abnormalities. J Hypertens. 2007;25:2296-300.

5. Bacchetti P. Current sample size conventions: flaws, harms, and alternatives. BMC Med. 2010;8:17.

6. Buchwald H, Avidor Y, Braunwald E, Jensen MD, Pories W, Fahrbach K, Schoelles K. Bariatric surgery: a systematic review and meta-analysis. JAMA. 2004;292:1724-37.

7. Cooper-DeHoff RM, Gong Y, Handberg EM, Bavry AA, Denardo SJ, Bakris GL, Pepine CJ. Tight blood pressure control and cardiovascular outcomes among hypertensive patients with diabetes and coronary artery disease. JAMA. 2010;304:61-8.

8. Curb JD, Pressel SL, Cutler JA, Savage PJ, Applegate WB, Black H, Camel G Davis BR, Frost PH, Gonzalez N, Guthrie G, Oberman A, Rutan GH, Stamler J. Effect of diuretic-based antihypertensive treatment on cardiovascular disease risk in older diabetic patients with isolated systolic hypertension. Systolic Hypertension in the Elderly Program Cooperative Research Group. JAMA. 1996;276:1886-92.

9. Donadelli SP, Salgado W Jr, Marchini JS, Schmidt A, Amato CA, Ceneviva R, Dos Santos JE, Nonino CB. Change in predicted 10-year cardiovascular risk following Roux-en-Y gastric bypass surgery: who benefits? Obes Surg. 2011;21:569-73.

10. Estacio RO, Jeffers BW, Gifford N, Schrier RW. Effect of blood pressure control on diabetic microvascular complications in patients with hypertension and type 2 diabetes. Diabetes Care. 2000;23:S54-S64.

11. Fernstrom JD, Courcoulas AP, Houck PR, Fernstrom MH. Long-term changes in blood pressure in extremely obese patients who have undergone bariatric surgery. Arch Surg. 2006;141:276-83.

12. Gastrointestinal surgery for severe obesity: National Institutes of Health Con sensus Development Conference Statement. Am J Clin Nutr. 1992;55: 615S-9S.

13. Hansson L, Zanchetti A, Carruthers SG, Dahlof B, Elmfeldt D, Julius S, Ménard J, Rahn KH, Wedel H, Westerling S. Effects of intensive blood-pressure lowering and low-dose aspirin in patients with hypertension: principal results of the Hypertension Optimal Treatment (HOT) randomised trial. Lancet. 1998;351:1755-62.

14. Heart Outcomes Prevention Evaluation (HOPE) Study investigators. Effects of ramipril on cardiovascular and microvascular outcomes in people with diabetes mellitus: results of the HOPE study and MICROHOPE substudy. Lancet. 2000;355:253-9.

15. Hinojosa MW, Varela JE, Smith BR, Che F, Nguyen NT. Resolution of systemic hypertension after laparoscopic gastric bypass. J Gastrointest Surg. 2009;13:793-7.

16. Ikramuddin S, Korner J, Lee WJ, Connett JE, Inabnet WB, Billington CJ, Thomas AJ, Leslie DB, Chong K, Jeffery RW, Ahmed L, Vella A, Chuang LM, Bessler M, Sarr MG, Swain JM, Laqua P, Jensen MD, Bantle JP. Roux-en-Y gastric bypass vs intensive medical management for the control of type 2 diabetes, hypertension, and hyperlipidemia: the Diabetes Surgery Study randomized clinical trial. JAMA. 2013;309:2240-9.
17. Le Roux CW, Aylwin SJ, Batterham RL, Borg CM, Coyle F, Prasad V, Shurey S, Ghatei MA, Patel AG, Bloom SR. Gut hormone profiles following bariatric surgery favor an anorectic state, facilitate weight loss, and improve metabolic parameters. Ann Surg. 2006;243:108-14

18. López-Jaramillo P, Sánchez RA, Diaz M, Cobos L, Bryce A, Parra Carrillo JZ Lizcano F, Lanas F, Sinay I, Sierra ID, Peñaherrera E, Bendersky M, Schmid H, Botero R, Urina M, Lara J, Foss MC, Márquez G, Harrap S, Ramírez AJ, Zanchetti A. Latin American consensus on hypertension in patients with diabetes type 2 and metabolic syndrome. J Hypertens. 2013;31:223-38.

19. Maggard MA, Shugarman LR, Suttorp M, Maglione M, Sugerman HJ, Livingston EH, Nguyen NT, Li Z, Mojica WA, Hilton L, Rhodes S, Morton SC, Shekelle PG Meta-analysis: surgical treatment of obesity. Ann Intern Med. 2005;142:547-59.

20. Nursalin A; Siregar P. A comprehensive management of hypertension among patients with metabolic syndrome: an evidence-based update. Med J Indones. 2013;22:189-94.

21. Pajecki D, Dalcanalle L, Souza de Oliveira CP, Zilberstein B, Halpern A, Garrido $\mathrm{AB} \mathrm{Jr}$, Cecconello I. Follow-up of Roux-en-Y gastric bypass patients at 5 or more years postoperatively. Obes Surg. 2007;17:601-7.

22. Pimenta GP, Saruwatari RT, Corrêa MR, Genaro PL, Aguilar-Nascimento JE Mortality, weight loss and quality of life of patients with morbid obesity: evaluation of the surgical and medical treatment after 2 years. Arq Gastr. 2010;47:263-9.

23. Reis CE, Alvarez-Leite JI, Bressan J, Alfenas RC. Role of bariatric-metabolic surgery in the treatment of obese type 2 diabetes with body mass index $<35 \mathrm{~kg} /$ $\mathrm{m}^{2}$ : a literature review. Diabetes Technol Ther. 2012;14:365-72.

24. Schauer PR, Kashyap SR, Wolski K, Brethauer SA, Kirwan JP, Pothier CE, Thomas S, Abood B, Nissen SE, Bhatt DL. Bariatric surgery versus intensive medical therapy in obese patients with diabetes. N Engl J Med. 2012;366:1567-76.

25. Sociedade Brasileira de Cardiologia; Sociedade Brasileira de Hipertensão; Sociedade Brasileira de Nefrologia. VI Brazilian Guidelines on Hypertension. Arq Bras Cardiol. 2010;95:1-51.

26. Staessen JA, Asmar R, De Buyzere M, Imai Y, Parati G, Shimada K, Stergiou G, Redón J, Verdecchia P; Participants of the 2001 Consensus Conference on Ambulatory Blood Pressure Monitoring. Participants of the 2001 Consensus Conference on Ambulatory Blood Pressure Monitoring. Task Force II. Blood pressure measurement and cardiovascular outcome. Blood Press Monit. 2001;6:355-70.

27. Sugerman HJ, Wolfe LG, Sica DA, Clore JN. Diabetes and hypertension in severe obesity and effects of gastric bypass-induced weight loss. Ann Surg. 2003;237:751-6.

28. Suzuki S, Ramos EJ, Gonçalves CG, Chen C, Meguid MM. Changes in GI hormones and their effect on gastric emptying and transit times after Roux-en-Y gastric bypass in rat model. Surgery. 2005;138:283-90.

29. Tuomilehto J, Rastenyte D, Birkenhäger WH, Thijs L, Antikainen R, Bulpitt CJ, Fletcher AE, Forette F, Goldhaber A, Palatini P, Sarti C, Fagard R. Effects of calcium-channel blockade in older patients with diabetes and systolic hypertension. Systolic Hypertension in Europe Trial Investigators. N Engl J Med. 1999;340:677-84.

30. UK Prospective Diabetes Study Group. Tight blood pressure control and risk of macrovascular and microvascular complications in type 2 diabetes: UKPDS 38 BMJ. 1998;317:703-13.

31. World Health Organization. Adherence to long term therapies: evidence for action. Genebra: WHO. 2003:1-211.

Received 21/9/2013 Accepted 1/11/2013 